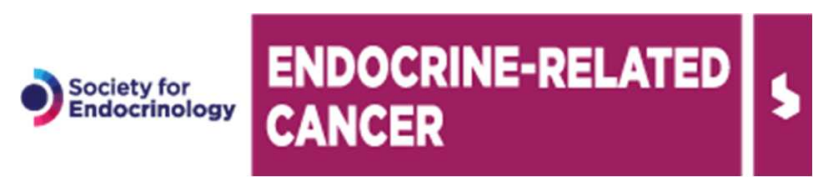

\title{
Differentiated thyroid cancer: Millions spent with no tangible gain?
}

\begin{tabular}{|r|l|}
\hline Journal: & Endocrine-Related Cancer \\
\hline Manuscript ID & ERC-17-0397.R1 \\
\hline Manuscript Type: & Research Paper \\
\hline Complete List of Authors: & $\begin{array}{l}\text { Furuya-Kanamori, Luis; Qatar University, Public Health } \\
\text { Sedrakyan, Art; Australian National University, Research School of } \\
\text { Population Health } \\
\text { Onitilo, Adedayo; Marshfield Clinic Weston Center, Hematology/Oncology; } \\
\text { University of Queensland, School of Population Health } \\
\text { Bagheri, Nasser; Australian National University, Research School of } \\
\text { Population Health } \\
\text { Glasziou, Paul; Bond University, Centre for Research in Evidence-Based } \\
\text { Practice } \\
\text { Doi, Suhail; University of Queensland, School of Population Health }\end{array}$ \\
\hline Keywords: & \begin{tabular}{l} 
Thyroid, thyroidectomy, over detection \\
\hline
\end{tabular} \\
\hline
\end{tabular}


1 Original Research

2

3 Differentiated thyroid cancer: Millions spent with no tangible gain?

4

5 Running title: Increase in DTC incidence and thyroidectomy

6

7 Luis Furuya-Kanamori $P h D^{1}$, Professor Art Sedrakyan $P h D^{2,3}$, Adedayo A. Onitilo $P h D^{4}$,

8 Nasser Bagheri $P h D^{2}$, Professor Paul Glasziou $P h D^{5}$, Professor Suhail A.R Doi $P h D^{1^{*}}$

$11{ }^{1}$ Department of Population Medicine, College of Medicine, Qatar University, Doha, Qatar

$12{ }^{2}$ Research School of Population Health, Australian National University, Canberra, ACT, 13 Australia

$14{ }^{3}$ Department of Healthcare Policy \& Research, Weill Cornell Medicine, New York, NY, 15 USA

$16{ }^{4}$ Department of Hematology/Oncology, Marshfield Clinic Weston Center, Weston, WI, USA

$17{ }^{5}$ Centre for Research in Evidence Based Practice, Bond University, Gold Coast, QLD,

18 Australia

$21 *$ Post-publication correspondence to:

Professor Suhail A.R. Doi MBBS, MMed, MClinEpid, PhD, FRCP

Department of Population Medicine, College of Medicine, Qatar University

28 Word count: 2821 


\section{Abstract}

30 Background: The incidence of differentiated thyroid cancer (DTC) has rapidly increased 31 worldwide over the last decades. It is unknown if the increase in diagnosis has been mirrored 32 by an increase in thyroidectomy rates with the concomitant economic impact that this would 33 have on the healthcare system.

Methods: DTC and thyroidectomy incidence as well as DTC specific mortality were modelled using Poisson regression in New South Wales (NSW), Australia per year and by sex. The incidence of 2002 was the point from which the increase in rates were assessed cumulatively over the subsequent decade. The economic burden of potentially avoidable thyroidectomies due to the increase in diagnosis was estimated as the product of the additional thyroidectomy procedures during a decade attributable to rates beyond those reported for 2002 and the national average hospital cost of an uncomplicated thyroidectomy in Australia.

Results: The incidence of both DTC and thyroidectomy doubled in NSW between 2003 and 2012, while the DTC specific mortality rate remained unchanged over the same period. Based on the 2002 incidence, the projected increase over 10 years (2003-2012) in thyroidectomy procedures was 2,196. This translates to an extra cost burden of over AUD\$18,600,000 in surgery-related healthcare expenditure over one decade in NSW.

Conclusions: Our findings suggest that, if this rise is solely attributable to overdetection, then the rising expenditure serves no additional purpose. Reducing unnecessary detection and a conservative approach to managing DTC are sensible and would lead to millions of dollars in savings and reduced harms to patients. 
55

56

57

\section{Introduction}

The incidence of thyroid cancer has increased worldwide 3- to 15 -fold over the last two decades, but with no significant increase in mortality (Pellegriti et al., 2013, Ahn et al., 2014). The increase in incidence is largely attributable to increased detection of differentiated thyroid cancer ([DTC] - i.e. papillary and follicular cancer) (Burgess and Tucker, 2006, Davies and Welch, 2006, Enewold et al., 2011). Studies have found that the penetrance of thyroid-cancer screening and fine-needle aspiration (FNA) strongly correlate with the observed increase in incidence (Burgess and Tucker, 2006, Ahn et al., 2014). Our recent investigation has also found that the increasing incidence of DTC is not mirrored by the prevalence of incidental DTC in autopsy studies which has remained stable since 1970 (Furuya-Kanamori et al., 2016). These findings, especially given the latter, establish the case for the absence of a true population level increase in tumorigenesis and supports the notion that the increasing burden is driven by increasing detection (Davies and Welch, 2006, Welch and Black, 2010, Brito et al., 2014, Furuya-Kanamori et al., 2016).

Alongside this increase in DTC incidence, there are reports that suggest that subsequent surgical intervention (i.e. thyroidectomy) is also increasing (Sung et al., 2014, Ahn and Welch, 2015). For example, DTC overdetection in small papillary carcinomas is leading to unnecessary thyroidectomies with no real survival advantage delivered to patients (Davies and Welch, 2006, Enewold et al., 2011). After surgery most patients would require lifelong thyroid-replacement therapy, while some patients may have complications from the surgical procedure such as hypoparathyroidism and paralysis of recurrent or superior laryngeal nerves (Hartl and Schlumberger, 2013). Therefore, in March 2014 a Physician Coalition for Prevention of Overdiagnosis of Thyroid Cancer in South Korea wrote an open letter to the public discouraging routine ultrasonographic screening, this recommendation led 
79 to a $40 \%$ decrease in thyroidectomies within the country in the subsequent year (Ahn and 80 Welch, 2015).

81 Similar to other countries, DTC incidence has rapidly increased over the last two 82 decades in Australia (Burgess, 2002, Haggar et al., 2012, Pandeya et al., 2016, Cancer 83 Australia); however, it is unknown if this has been paralleled by an increase in surgical 84 intervention rates. We therefore undertook an evaluation of the diagnostic, surgical, and 85 mortality trend data for DTC from New South Wales (NSW) to estimate the increase in 86 economic burden of these surgical interventions to the Australian healthcare system and its 87 impact on DTC specific mortality rates during the last decade. 


\section{Materials and methods}

The study was approved by the Australian National University - Science \& Medical Delegated Ethics Review Committee (\#2016/030) and conforms to the data-use agreement from the NSW Health Department.

\section{Data sources and study population}

Aggregated data from patients diagnosed with thyroid cancer (Cancer Institute NSW, 2016b) and thyroid cancer specific deaths (Cancer Institute NSW, 2016c) in NSW between January 1982 and December 2012 were retrieved from the Cancer Institute NSW. The NSW Cancer Registry (NSWCR) is managed by the Cancer Institute NSW. The NSWCR is a population-based cancer registry that contains records of people with malignant neoplasms in NSW since 1972. Notification of new cancer cases and cancer deaths is legally required in NSW and the NSWCR receives data from public and private hospitals, nursing homes, public and private pathology laboratories, and the Registry of Births, Deaths and Marriage.

Data from patients with thyroid gland malignancies (ICD-10-CM C73) that underwent partial (ICD-10-AM 30306-00, 30306-01, 30308-00, 30310-00, 90046-00) or total (ICD-10AM 30296-00, 30296-01, 90046-01, 90046-02) thyroidectomies between January 2002 and December 2012 in NSW were extracted from the Admitted Patient Data Collection (APDC). Thyroidectomies with indications other than thyroid cancer (i.e. thyrotoxicosis ICD-10-AM 30309-00) were excluded from the analysis. To avoid the inclusion of recurrent cases of surgical procedures (e.g. partial thyroidectomy followed by a total thyroidectomy - ICD-10AM 30297-00, 30297-01, 30297-02) and over estimating the incidence of patients that underwent a thyroidectomy; if a patient had more than one surgical procedure, only the first procedure was included for the analysis. The APDC is administered by the NSW Health Department. The APDC data provides reasonably accurate information on procedures and 
113 comorbidities (Goldsbury et al., 2011, Goldsbury et al., 2012). A detailed description of the

114 APDC scope, collection methodology, maintenance, and data accuracy is described 115 elsewhere (Australian Bureau of Statistics, 2008).

116 
117

118

119

120

121

122

123

124

125

126

127

128

129

130

131

132

133

134

135

136

137

138

139

140

141

\section{Statistical analyses}

Thyroid cancer cases, thyroidectomy procedures, and thyroid cancer specific mortality in NSW were categorized by year of event (diagnosis or surgical procedure) and sex. New events were counted within these categories. The population at risk, the population in NSW, was extracted from the Australian Bureau of Statistics (ABS) and stratified by year and sex. It should be noted that differentiation of DTC from all thyroid cancers was not possible and this applies to thyroidectomy as well. Although, the analyses were not DTCspecific, yet the estimated incidence rates reported are deemed to be those for DTC as they should closely match the DTC-specific incidence due to the small proportion ( $10 \%$ or less) of other histological types of cancers (i.e. medullary and anaplastic) expected in such cohorts during the same period (Pandeya et al., 2016). This seems justified since an analysis of a previous dataset of ours with only DTC confirms that DTC mortality trends remain comparable to those reported here (Mankarios et al., 2014). All subsequent references to DTC should be understood to refer to DTC without exclusion of the other thyroid cancers.

Poisson regressions models using robust standard errors and the population as the exposed population at risk were built to model the rates for incident DTC, incident thyroidectomies, and thyroid cancer specific mortality in NSW by including an interaction term for continuous year and sex. The predicted number of cases per year and by sex from the fitted models were used to estimate the incidence of DTC and DTC specific mortality from 1982 to 2012 and thyroidectomy procedures from 2002 to 2012 in NSW per 100,000 population.

The rate observed in 2002 was deemed the baseline from which the increase in the rate of thyroidectomy was computed over the subsequent decade. The increase in thyroidectomy rates was therefore estimated for the period 2003-2012 as the difference from the baseline had it remained at the 2002 levels. To compute the additional number of surgical 
142 procedures over the last decade, the modelled difference in rates (from 2002 levels) was

143 multiplied by the population at risk in NSW during each year.

144 The national average hospital cost of uncomplicated thyroidectomy for 2012-2013 in 145 Australia was AUD\$ 8,500 (Independent Hospital Pricing Authority, 2015). The economic 146 burden of potentially avoidable thyroidectomy due to the increase in diagnosis to the 147 Australian healthcare system was estimated as the product of the additional thyroidectomy 148 within the decade after 2002 and the national average hospital cost of an uncomplicated 149 thyroidectomy. We did not estimate the costs of complications or ongoing treatment such as 150 thyroid replacement. All statistical analyses were conducted using Stata ${ }^{\circledR}$ SE, version 14 151 (Stata Corporation; College Station, TX). 


\section{Results}

Between 1982 and 2012, 13,131 patients were diagnosed with DTC in NSW and 859

154 had a thyroid cancer specific mortality. The majority of diagnosed patients were females $155(\mathrm{n}=9,877 ; 75 \cdot 1 \%) \cdot 6,790$ thyroidectomies were recorded among patients with DTC between 1562002 and 2012 in NSW hospitals. The majority of the thyroidectomy procedures were 157 performed in women $(n=5,485 ; 80.89 \%)$ and the median age of the patients was 50 years 158 (IQR 40-62 years) (Table 1).

The estimated DTC incidence per 100,000 population increased from 3.4 (females) and 1.2 (males) in 1982 to 20.6 (females) and 6.8 (males) in 2012. The estimated thyroidectomy incidence per 100,000 population increased from $9 \cdot 1$ (females) and $3 \cdot 0$ (males) in 2002 to 18.6 (females) and 6.0 (males) in 2012; while the estimated thyroid cancer specific mortality rate demonstrated no change over this period or indeed the prior two decades (Figures 1 and $2 \&$ Supplementary material).

During the decade of interest (2003-2012), there was a two-fold increase in both, DTC and thyroidectomies among females and males. Since, the percentage of DTC 167 diagnosed patients getting a thyroidectomy has remained stable, it follows therefore that watchful waiting is not happening at a greater rate than previously despite DTC incidence steeply rising (Figures $1 \& 2$ ). Based on this increasing incidence, the projected increase in 170 thyroidectomy was 2,196 (1,667 females; 529 males) cases more than would have happened 171 if thyroidectomies rates had remained stable subsequent to 2002. This translates to an 172 increase of AUD\$ $18,666,000$ (\$14,169,500 in females; $\$ 4,496,500$ in males) in surgery173 related healthcare expenditure over one decade in NSW (Figures 1 and 2). 


\section{Discussion}

DTC incidence has increased to epidemic proportions worldwide over the last few decades. Overdetection has not only increased DTC incidence, but it has also led to a concurrent increase in thyroidectomy procedures with a huge economic burden on the healthcare system (Table 2). Over the last decade, we estimate that the number of potentially avoidable thyroidectomies performed in NSW was 2,196. The increase in thyroidectomy procedures in NSW over this decade actually approximates the total estimated number of new cases of thyroid cancer diagnosed Australia-wide in 2016 (2098 new cases) (Cancer Australia). DTC specific mortality in Australia however has remained essentially unchanged over the last 30 years (Cancer Australia) and among the thyroid cancer specific deaths recorded in 2012 in NSW, half of them occurred in patients aged 80 years or above (Cancer Institute NSW, 2016a). These figures amount to a huge excess in diagnosis and intervention that do not lead to increased survival for patients (Davies and Welch, 2006, Ito et al., 2010, Sugitani et al., 2010, Welch and Black, 2010, Ito et al., 2014, Furuya-Kanamori et al., 2016, Cancer Australia).

It should be emphasised that we base our conclusion regarding the lack of tangible clinical gain only on the specific mortality rate having remained unchanged. There is, however, no expectation that intervention may decrease morbidity that does not lead to death. Unfortunately, these interventions themselves have been associated with morbidities. In fact, paradoxically there is likely to be an increase in morbidity related to treatment if patients subject to such (over)diagnosis are given the standard management for thyroid cancer which includes surgical resection and/or radioiodine therapy (Doi and Woodhouse, 2000, Doi et al., 2007, Haugen et al., 2015). Surgical complications may arise and include hypoparathyroidism, a life-threatening condition that requires intensive monitoring and therapy with calcium and vitamin D; laryngeal nerve palsy which will results in voice 
199 change; and/or require tracheotomy in cases of bilateral nerve damage. Even when the 200 surgery is complication free, most of the patients will require lifelong surveillance, and thyroid hormone suppression or replacement which may have longer term metabolic implications (Hartl and Schlumberger, 2013).

It could be argued that the increased thyroid cancer diagnosis in recent years is associated with stable mortality because of improvement in diagnosis and management over time. However, Davies and Welch have pointed out that this is not likely to be true (Davies and Welch, 2014) because for mortality to remain stable, improvements (in diagnostic techniques and disease management) have to precisely mirror the increase in thyroid incidence. Thus, improvements occurring at a faster or slower rate than changes in incidence rate would certainly alter mortality rates and to assume an exact match between the rising incidence and the improvements over 30 years is highly implausible. In a previous study, we demonstrated that the reservoir of incidental DTC has remained stable since 1970 suggesting that population level of tumorigenesis has remained unchanged (Furuya-Kanamori et al., 2016). Therefore, the most reasonable explanation for the rising thyroid cancer incidence with stable mortality is that subclinical DTC is increasingly being detected due to the improvements in diagnostic techniques, but these newly diagnosed subclinical cases may not progress or will progress so slowly that the patient is more likely to die from other causes. burden, while late diagnosis of clinically significant thyroid cancer could worsen clinical outcome. The current evidence does make the case for the development of strategies to reduce overdetection (the thyroid should not be examined without a specific indication) as well as implementation of a more conservative approach to nodule diagnosis through active surveillance leading on to intervention if thyroid nodules demonstrate progression (i.e. size and/or characteristics) (Leboulleux et al., 2016). At this point, it is not clear which patients 
224 are eligible for active surveillance, further studies are required to accurately discriminate

225

226

227

228

patients who need to undergo thyroid nodule biopsy or active surveillance; as well as to recognise prognostic factors that would warrant early intervention among the subset of thyroid cancer patients with more aggressive disease. Currently, nodule size is an important factor in such decision making, along with family history, exposure to radiation, and age of the patient (>45 years) (Onitilo et al., 2009, Mankarios et al., 2014, Haugen et al., 2015, Hoang et al., 2015). Although, differentiation of DTC histopathology (papillary versus follicular) does not seem to play a major role in decision making, FNA cytology may be indicated if there are signs of progression or to differentiate DTC from other types of carcinomas (i.e. medullary and anaplastic) given the different prognosis associated with the latter.

In terms of health services expenditure, thyroid gland surgeries in Australia cost on average AUD\$ 8,500; however when there are surgical complications, this amount rapidly increases to over AUD \$ 15,000 (Independent Hospital Pricing Authority, 2015). We used the average cost of uncomplicated thyroidectomies, which provides a conservative economic estimate of the burden of increasing diagnosis. Future economic evaluations would need to take into account additional costs such as diagnosis (e.g. FNA and histopathology examination), complications during the surgical intervention (e.g. ICU admission), hormone replacement therapy, and outpatient consultations. Thus, a deferral of surgery can be expected to lead to significant savings in projected healthcare expenditure of at least AUD\$ 4 million per year in the state of NSW. This cost saving over 10 years is weighted heavily towards the later part of the decade and is a very conservative estimate as it does not take into account the treatment factors mentioned previously and of course the emotional burden on patients. Furthermore, given that the DTC incidence rise has been ongoing since the 1980s, our estimate over only the last decade is probably a considerable underestimate of the 
249 economic burden as overdetection/thyroidectomy may have increased 4-fold rather than just 250 2-fold. While, the data suggest a clear economic case for surveillance rather than intervention, and accumulated evidence from several studies suggest that this would be a safe approach (Ito et al., 2010, Sugitani et al., 2010, Brito et al., 2014, Ito et al., 2014); the exact process that should be adopted requires further evidence from prospective clinical studies, and funding for such studies must be made a priority.

Our findings should be considered in the light of a few limitations. An important one was the inability to conduct sub-group analyses by age group, patient ethnicity, tumour size, and histopathology. However, we were able to stratify the analyses by sex, which is known to be one of the strongest predictors of DTC incidence and thyroidectomy. We also make the assumption based on our previous work that the rising trends are representative of overdiagnosis (Furuya-Kanamori et al., 2016). There have been studies that seem to disagree and for example, from a SEER database analysis by Enewold et al. (2009) amongst White women, the rate of increase for papillary thyroid carcinoma $>5 \mathrm{~cm}$ was similar to that for smaller thyroid cancer. Another study from Spain by Rego-Iraeta et al. (2009) also reported that the rate of rise in thyroid cancer was observed across all tumour sizes. We agree with the latter that the incidence of all sizes are rising but a re-analysis of our previous data (Mankarios et al., 2014) stratified by tumour size and gender clearly demonstrates that the rate of rise decreases with increasing size, though all sizes are increasingly detected (data not shown). We believe that this again is consistent with overdiagnosis. Nevertheless, it is important to distinguish indolent tumours from clinically significant tumours (where delays in diagnosis are important) and this requires guidance from future studies regarding delineation of criteria for patients who need to undergo thyroid nodule biopsy for diagnosis of thyroid cancer (to avoid over-diagnosis of indolent thyroid cancer). Such criteria would likely

273 be prognostic factors that would assist in identification of more advanced thyroid cancers 
274 thus avoiding fears that clinicians may delay treatment and increase recurrent/persistent 275 disease within a selected sub-set of thyroid cancer patients with more aggressive disease.

276 In conclusion, the evidence base for avoidable costs to healthcare is clear and savings 277 expected are substantial from a conservative approach to both thyroid examination (only 278 when indicated) and management of thyroid cancer when detected. Current evidence suggests 279 that watchful waiting is a safe route for management of many of the latter patients if due 280 surveillance is properly managed. What remains to be mapped out is who exactly should be 281 offered active surveillance and the criteria for subsequent intervention. 


\section{Declaration of interest}

283 The authors have no conflicts of interest in the authorship or publication of this article.

285 Funding

286 None

287

288 Authors' contributions

289 LFK and SARD contributed to the conception and design of the study. AS and LFK assisted 290 with data acquisition. LFK conducted the statistical analyses. LFK and SARD drafted the 291 manuscript. AS, AAO, NB, and PG critically revised the manuscript. LFK, AS, AAO, NB, 292 PG, and SARD read and approved the final version of the manuscript and agreed to be fully 293 accountable for ensuring the integrity and accuracy of the work. 
300

301

302

303

304

305

306

307

308

309

310

311

312

\section{References}

AHN, H. S., KIM, H. J. \& WELCH, H. G. 2014. Korea's thyroid-cancer "epidemic"screening and overdiagnosis. $N$ Engl J Med 371: 1765-7.

AHN, H. S. \& WELCH, H. G. 2015. South Korea's thyroid-cancer "Epidemic"- Turning the tide. N Engl J Med 373: 2389-90.

AUSTRALIAN BUREAU OF STATISTICS. 2008. NSW Health Department, Admitted Patient Data Collection [Online]. Available: http://www.abs.gov.au/AUSSTATS/abs@.nsf/Lookup/1368.1Explanatory\%20Notes1 $\underline{452007}$ [Accessed September 2017].

BRITO, J. P., DAVIES, L., ZEBALlOS-PALACIOS, C., MORRIS, J. C. \& MONTORI, V. M. 2014. Papillary lesions of indolent course: reducing the overdiagnosis of indolent papillary thyroid cancer and unnecessary treatment. Future Oncol 10: 1-4.

BURGESS, J. R. 2002. Temporal trends for thyroid carcinoma in Australia: an increasing incidence of papillary thyroid carcinoma (1982-1997). Thyroid 12: 141-9.

BURGESS, J. R. \& TUCKER, P. 2006. Incidence trends for papillary thyroid carcinoma and their correlation with thyroid surgery and thyroid fine-needle aspirate cytology. Thyroid 16: 47-53.

CANCER AUSTRALIA. Thyroid cancer [Online]. Available: https://canceraustralia.gov.au/affected-cancer/cancer-types/thyroid-cancer/thyroidcancer-statistics [Accessed September 2017].

CANCER INSTITUTE NSW. 2016a. Thyroid cancer [Online]. Available: https://www.cancerinstitute.org.au/understanding-cancer/cancer-in-nsw/thyroidcancer [Accessed September 2017].

CANCER INSTITUTE NSW. 2016b. Thyroid cancer - Age Standardised Incidence Rates [Online]. Available: http://www.statistics.cancerinstitute.org.au/trends/trends_incid_C73 extall_NSW.htm [Accessed September 2017].

CANCER INSTITUTE NSW. 2016c. Thyroid cancer - Age Standardised Mortality Rates [Online].

Available: 

http://www.statistics.cancerinstitute.org.au/trends/trends_mort_C73 extall_NSW.htm [Accessed September 2017].

DAVIES, L. \& WELCH, H. 2014. Davies and welch draw unfounded conclusions about thyroid cancer from epidemiological data-reply. JAMA Otolaryngol Head Neck Surg 140: 679 .

DAVIES, L. \& WELCH, H. G. 2006. Increasing incidence of thyroid cancer in the United States, 1973-2002. JAMA 295: 2164-7.

DOI, S. A. \& WOODHOUSE, N. J. 2000. Ablation of the thyroid remnant and 131I dose in differentiated thyroid cancer. Clin Endocrinol (Oxf) 52: 765-73.

DOI, S. A. R., WOODHOUSE, N. J., THALIB, L. \& ONITILO, A. 2007. Ablation of the Thyroid Remnant and I-131 Dose in Differentiated Thyroid Cancer: A Meta-Analysis Revisited. Clin Med Res 5: 87-90.

ENEWOLD, L., ZHU, K., RON, E., MARROGI, A. J., STOJADINOVIC, A., PEOPLES, G. E. \& DEVESA, S. S. 2009. Rising thyroid cancer incidence in the United States by demographic and tumor characteristics, 1980-2005. Cancer Epidemiol Biomarkers Prev 18: 784-91.

ENEWOLD, L. R., ZHOU, J., DEVESA, S. S., BERRINGTON DE GONZALEZ, A., ANDERSON, W. F., ZAHM, S. H., STOJADINOVIC, A., PEOPLES, G. E., MARROGI, A. J., POTTER, J. F., MCGLYNN, K. A. \& ZHU, K. 2011. Thyroid cancer incidence among active duty U.S. military personnel, 1990-2004. Cancer Epidemiol Biomarkers Prev 20: 2369-76.

FURUYA-KANAMORI, L., BELL, K. J., CLARK, J., GLASZIOU, P. \& DOI, S. A. 2016. Prevalence of Differentiated Thyroid Cancer in Autopsy Studies Over Six Decades: A Meta-Analysis. J Clin Oncol 34: 3672-9.

GOldSBURY, D. E., ARMSTRONG, K., SimOnElla, L., ARMSTRONG, B. K. \& O'CONNELL, D. L. 2012. Using administrative health data to describe colorectal and lung cancer care in New South Wales, Australia: a validation study. BMC Health Serv Res 12: 1472. 
GOldSBURY, D. E., SMITH, D. P., ARMSTRONG, B. K. \& O'CONNELL, D. L. 2011. Using linked routinely collected health data to describe prostate cancer treatment in New South Wales, Australia: a validation study. BMC Health Services Res 11: 253.

HAGGAR, F. A., PREEN, D. B., PEREIRA, G., HOLMAN, C. D. \& EINARSDOTTIR, K. 2012. Cancer incidence and mortality trends in Australian adolescents and young adults, 1982-2007. BMC Cancer 12: 151.

HARTL, D. M. \& SCHLUMBERGER, M. 2013. Extent of Thyroidectomy and Incidence of Morbidity: Risk-appropriate Treatment. In: MICCOLI, P., TERRIS, D. J., MINUTO, M. N. \& SEYBT, M. W. (eds.) Thyroid Surgery: Preventing and Managing Complications. Oxford: Wiley-Blackwell.

HAUGEN, B. R. M., ALEXANDER, E. K., BIBLE, K. C., DOHERTY, G., MANDEL, S. J., NIKIFOROV, Y. E., PACINI, F., RANDOLPH, G., SAWKA, A., SCHLUMBERGER, M., SCHUFF, K. G., SHERMAN, S. I., SOSA, J. A., STEWARD, D., TUTTLE, R. M. M. \& WARTOFSKY, L. 2015. 2015 American Thyroid Association management guidelines for adult patients with thyroid nodules and differentiated thyroid cancer. Thyroid 26: 1-133.

HOANG, J. K., LANGER, J. E., MIDDlETON, W. D., WU, C. C., HAMMERS, L. W., CRONAN, J. J., TESSLER, F. N., GRANT, E. G. \& BERLAND, L. L. 2015. Managing incidental thyroid nodules detected on imaging: white paper of the ACR Incidental Thyroid Findings Committee. J Am Coll Radiol 12: 143-50.

INDEPENDENT HOSPITAL PRICING AUTHORITY. 2015. National Hospital Cost Data Collection Australian Public Hospitals Cost Report 2012-2013, Round 17 [Online]. Available:

https://www.ihpa.gov.au/sites/g/files/net636/f/publications/nhcde cost_report_20122013 round_17_0.pdf [Accessed September 2017].

ITO, Y., MIYAUCHI, A., INOUE, H., FUKUSHIMA, M., KIHARA, M., HIGASHIYAMA, T., TOMODA, C., TAKAMURA, Y., KOBAYASHI, K. \& MIYA, A. 2010. An observational trial for papillary thyroid microcarcinoma in Japanese patients. World $J$ Surg 34: 28-35. 
ITO, Y., MIYAUCHI, A., KIHARA, M., HIGASHIYAMA, T., KOBAYASHI, K. \& MIYA, A. 2014. Patient age is significantly related to the progression of papillary microcarcinoma of the thyroid under observation. Thyroid 24: 27-34.

LEBOUlleUX, S., TUTTLE, R. M., PACINI, F. \& SCHLUMBERGER, M. 2016. Papillary thyroid microcarcinoma: time to shift from surgery to active surveillance? Lancet Diabetes Endocrinol 4: 933-42.

MANKARIOS, D., BAADE, P., YOUL, P., MORTIMER, R. H., ONITILO, A. A., RUSSELL, A. \& DOI, S. A. 2014. Validation of the QTNM staging system for cancer-specific survival in patients with differentiated thyroid cancer. Endocrine 46: 300-8.

ONITILO, A. A., ENGEL, J. M., LUNDGREN, C. I., HALL, P., THALIB, L. \& DOI, S. A. 2009. Simplifying the TNM system for clinical use in differentiated thyroid cancer. $J$ Clin Oncol 27: 1872-8.

PANDEYA, N., MCLEOD, D. S., BALASUBRAMANIAM, K., BAADE, P. D., YOUL, P. H., BAIN, C. J., ALLISON, R. \& JORDAN, S. J. 2016. Increasing thyroid cancer incidence in Queensland, Australia 1982-2008 - true increase or overdiagnosis? Clin Endocrinol 84: 257-64.

PELLEGRITI, G., FRASCA, F., REGALBUTO, C., SQUATRITO, S. \& VIGNERI, R. 2013. Worldwide increasing incidence of thyroid cancer: Update on epidemiology and risk factors. J Cancer Epidemiol 2013: 965212.

REGO-IRAETA, A., PEREZ-MENDEZ, L. F., MANTINAN, B. \& GARCIA-MAYOR, R. V. 2009. Time trends for thyroid cancer in northwestern Spain: true rise in the incidence of micro and larger forms of papillary thyroid carcinoma. Thyroid 19: 33340.

SUGITANI, I., TODA, K., YAMADA, K., YAMAMOTO, N., IKENAGA, M. \& FUJIMOTO, Y. 2010. Three distinctly different kinds of papillary thyroid microcarcinoma should be recognized: our treatment strategies and outcomes. World J Surg 34: 1222-31. 
420

421

422

423

SUNG, M. W., PARK, B., AN, S. Y., HAH, J. H., JUNG, Y. H. \& CHOI, H. G. 2014. Increasing thyroid cancer rate and the extent of thyroid surgery in Korea. PLoS One 9: e113464.

WELCH, H. G. \& BLACK, W. C. 2010. Overdiagnosis in cancer. J Natl Cancer Inst 102: 605-13.

Table Title

Table 1. Patient's characteristics

Table 2. Worldwide trends in thyroid cancer incidence, thyroidectomy rate and mortality rate

\section{Figure Legend}

Figure 1. Observed (circles) and modelled (dashed lines) incidence per 100,000 for DTC (blue), thyroidectomies (red), and DTC specific mortality (green) over time in females. Gray shaded area represents the excess (potentially avoidable) thyroidectomies performed due to the increase in diagnosis over the last decade and the excess in surgery-related healthcare expenditure associated with this.

Figure 2. Observed (circles) and modelled (dashed lines) incidence per 100,000 for DTC (blue), thyroidectomies (red), and DTC specific mortality (green) over time in males. Gray shaded area represents the excess (potentially avoidable) thyroidectomies performed due to the increase in diagnosis over the last decade and the excess in surgery-related healthcare expenditure associated with this. 
Table 1. Patient's characteristics

\begin{tabular}{|c|c|c|c|}
\hline & $\begin{array}{l}\text { Thyroid cancer } \\
\text { cases } \\
(\mathrm{n}=13,131)\end{array}$ & $\begin{array}{l}\text { Thyroidectomies } \\
(\mathrm{n}=6,790)\end{array}$ & $\begin{array}{l}\text { Thyroid cancer } \\
\text { specific } \\
\text { mortality } \\
(\mathrm{n}=859)\end{array}$ \\
\hline Female sex & $9,877(75 \cdot 2 \%)$ & $5,147(75 \cdot 8 \%)$ & $513(59 \cdot 7 \%)$ \\
\hline Age in years, median (IQR) & - & $50(40-62)$ & - \\
\hline \multicolumn{4}{|l|}{ Type of thyroidectomy } \\
\hline Partial & - & $1,305(19 \cdot 2 \%)$ & - \\
\hline Total & - & $5,485(80 \cdot 8 \%)$ & - \\
\hline \multicolumn{4}{|l|}{ Year } \\
\hline 1982-85 & 552 & - & 90 \\
\hline $1986-89$ & 693 & - & 96 \\
\hline $1990-93$ & 977 & - & 92 \\
\hline 1994-97 & 1290 & - & 103 \\
\hline 1998-01 & 1675 & - & 107 \\
\hline 2002-05 & 2217 & 1823 & 132 \\
\hline 2006-09 & 2872 & 2453 & 134 \\
\hline 2010-2012 & 2845 & 2514 & 105 \\
\hline
\end{tabular}


Table 2. Worldwide trends in thyroid cancer incidence, thyroidectomy rate and mortality rate

\begin{tabular}{llll}
\hline Country & Thyroid cancer incidence & Thyroidectomy rate & Mortality rate \\
& & & \\
\hline Canada & $\begin{array}{l}\text { Increased 5-fold } \\
(1970-2012)\end{array}$ & $\begin{array}{l}\text { Increased 13\% } \\
(2003-2011)\end{array}$ & $\begin{array}{l}\text { Remained stable } \\
(1970-2012)\end{array}$ \\
South Korea & $\begin{array}{l}\text { Increased 13-fold } \\
(1993-2011)\end{array}$ & $\begin{array}{l}\text { Increased 10-fold* } \\
(2001-2012)\end{array}$ & $\begin{array}{l}\text { Remained stable } \\
(1993-2011)\end{array}$ \\
Switzerland & $\begin{array}{l}\text { Increased 2- and 1.5- fold } \\
\text { in females and males, } \\
\text { respectively } \\
\text { Increased 4- and 3-fold }\end{array}$ & $\begin{array}{l}\text { Decreased by 30\% } \\
\text { in females and males, } \\
\text { respectively } \\
(1998-2012)\end{array}$ & $\begin{array}{l}\text { (1998-2012) } \\
\text { Increased 39\%* }\end{array}$ \\
USA & $\begin{array}{l}\text { Increased 3.6-fold } \\
(1974-2013)\end{array}$ & $\begin{array}{l}\text { Increased 15\% } \\
(1996-2006)\end{array}$ \\
UK & $\begin{array}{l}\text { Increased 2.2-fold } \\
(1993-2014)\end{array}$ & $\begin{array}{l}\text { Remained stable } \\
(1993-2014)\end{array}$ \\
\hline
\end{tabular}

* Number of thyroidectomies, not rates 


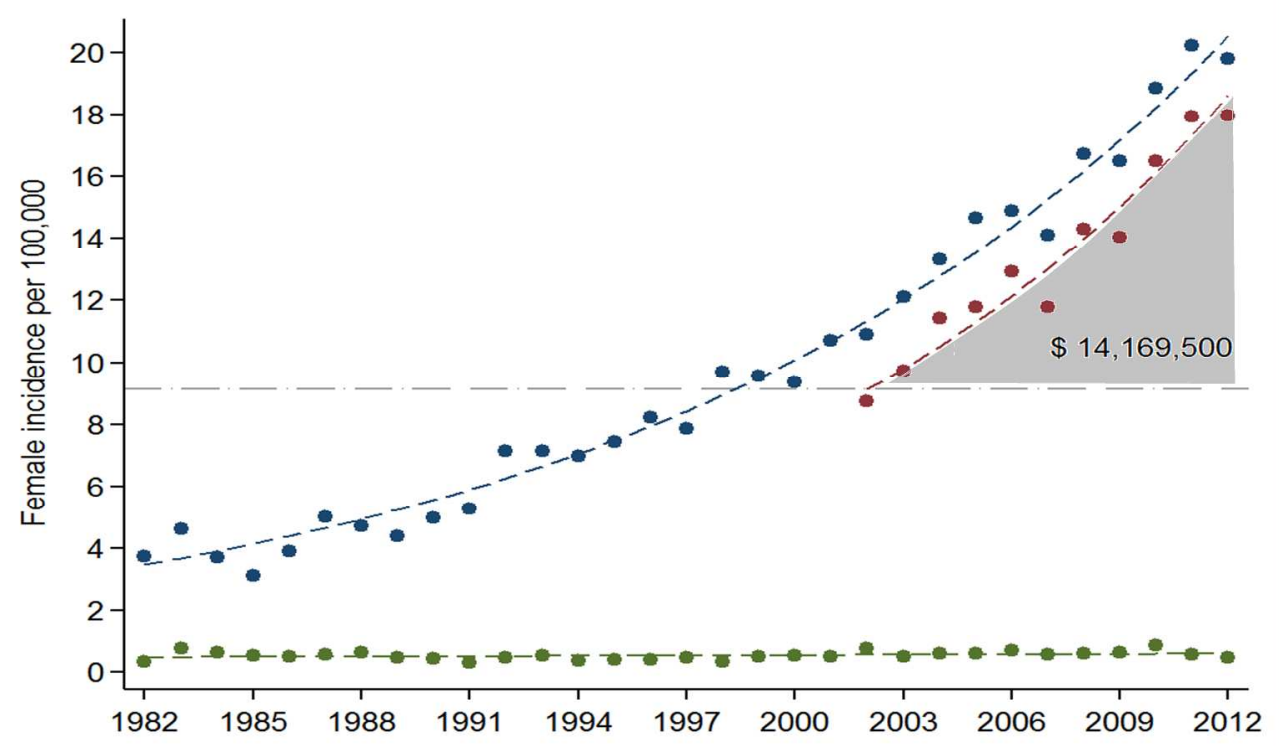

Figure 1. Observed (circles) and modelled (dashed lines) incidence per 100,000 for DTC (blue), thyroidectomies (red), and DTC specific mortality (green) over time in females. Gray shaded area represents the excess (potentially avoidable) thyroidectomies performed due to the increase in diagnosis over the last decade and the excess in surgery-related healthcare expenditure associated with this.

$1765 \times 1051 \mathrm{~mm}(96 \times 96 \mathrm{DPI})$ 


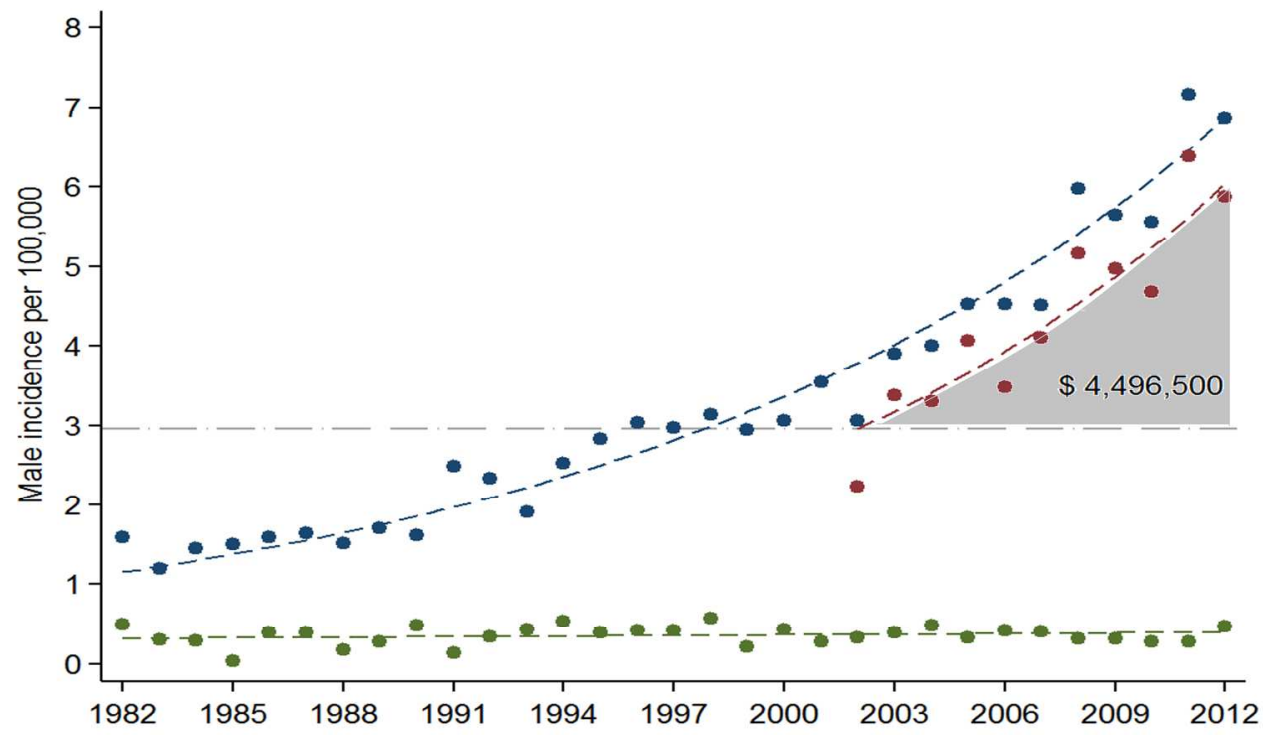

Figure 2. Observed (circles) and modelled (dashed lines) incidence per 100,000 for DTC (blue), thyroidectomies (red), and DTC specific mortality (green) over time in males. Gray shaded area represents the excess (potentially avoidable) thyroidectomies performed due to the increase in diagnosis over the last decade and the excess in surgery-related healthcare expenditure associated with this.

$1765 \times 1051 \mathrm{~mm}(96 \times 96 \mathrm{DPI})$ 


\section{Supplementary material}

Table S1. Estimated incidence and its $95 \%$ confidence interval of thyroid cancer, thyroidectomy, and thyroid cancer specific mortality per 100,000 population by sex.

\begin{tabular}{|c|c|c|c|c|c|c|}
\hline \multirow[t]{2}{*}{ Year } & \multicolumn{3}{|l|}{ Female } & \multicolumn{3}{|l|}{ Males } \\
\hline & Thyroid cancer & Thyroidectomy & $\begin{array}{l}\text { Thyroid cancer } \\
\text { mortality }\end{array}$ & Thyroid cancer & Thyroidectomy & $\begin{array}{l}\text { Thyroid cancer } \\
\text { mortality }\end{array}$ \\
\hline 1982 & $3 \cdot 5(3 \cdot 2-3 \cdot 7)$ & 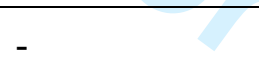 & $0 \cdot 5(0 \cdot 4-0 \cdot 6)$ & $1 \cdot 2(1 \cdot 1-1 \cdot 2)$ & - & $0 \cdot 3(0 \cdot 3-0 \cdot 4)$ \\
\hline 1983 & $3 \cdot 7(3 \cdot 5-3 \cdot 9)$ & - & $0 \cdot 5(0 \cdot 4-0 \cdot 6)$ & $1 \cdot 2(1 \cdot 2-1 \cdot 3)$ & - & $0 \cdot 3(0 \cdot 3-0 \cdot 4)$ \\
\hline 1984 & $3 \cdot 9(3 \cdot 7-4 \cdot 1)$ & - & $0 \cdot 5(0 \cdot 4-0 \cdot 6)$ & $1 \cdot 3(1 \cdot 2-1 \cdot 4)$ & - & $0 \cdot 3(0 \cdot 3-0 \cdot 4)$ \\
\hline 1985 & $4 \cdot 1(3 \cdot 9-4 \cdot 4)$ & - & $0 \cdot 5(0 \cdot 4-0 \cdot 6)$ & $1 \cdot 4(1 \cdot 3-1 \cdot 5)$ & - & $0 \cdot 3(0 \cdot 3-0 \cdot 4)$ \\
\hline 1986 & $4 \cdot 4(4 \cdot 2-4 \cdot 6)$ & _ & $0.5(0 \cdot 4-0 \cdot 6)$ & $1 \cdot 5(1 \cdot 4-1 \cdot 6)$ & _ & $0 \cdot 3(0 \cdot 3-0 \cdot 4)$ \\
\hline 1987 & $4 \cdot 7(4 \cdot 4-4 \cdot 9)$ & - & $0 \cdot 5(0 \cdot 4-0 \cdot 6)$ & $1 \cdot 6(1 \cdot 5-1 \cdot 6)$ & - & $0 \cdot 3(0 \cdot 3-0 \cdot 4)$ \\
\hline 1988 & $4 \cdot 9(4 \cdot 7-5 \cdot 2)$ & - & $0 \cdot 5(0 \cdot 4-0 \cdot 6)$ & $1 \cdot 6(1 \cdot 6-1 \cdot 7)$ & - & $0 \cdot 3(0 \cdot 3-0 \cdot 4)$ \\
\hline 1989 & $5 \cdot 2(5 \cdot 0-5 \cdot 5)$ & - & $0 \cdot 5(0 \cdot 4-0 \cdot 6)$ & $1 \cdot 8(1 \cdot 7-1 \cdot 8)$ & - & $0 \cdot 3(0 \cdot 3-0 \cdot 4)$ \\
\hline 1990 & $5 \cdot 6(5 \cdot 3-5 \cdot 8)$ & - & $0 \cdot 5(0 \cdot 4-0 \cdot 6)$ & $1 \cdot 9(1 \cdot 8-2 \cdot 0)$ & - & $0 \cdot 3(0 \cdot 3-0 \cdot 4)$ \\
\hline 1991 & $5 \cdot 9(5 \cdot 7-6 \cdot 2)$ & - & $0 \cdot 5(0 \cdot 5-0 \cdot 6)$ & $2 \cdot 0(1 \cdot 9-2 \cdot 1)$ & 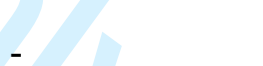 & $0 \cdot 3(0 \cdot 3-0 \cdot 4)$ \\
\hline 1992 & $6 \cdot 3(6 \cdot 0-6 \cdot 5)$ & - & $0 \cdot 5(0 \cdot 5-0 \cdot 6)$ & $2 \cdot 1(2 \cdot 0-2 \cdot 2)$ & - & $0 \cdot 3(0 \cdot 3-0 \cdot 4)$ \\
\hline 1993 & $6 \cdot 6(6 \cdot 4-6 \cdot 9)$ & - & $0 \cdot 5(0 \cdot 5-0 \cdot 6)$ & $2 \cdot 2(2 \cdot 1-2 \cdot 3)$ & - & $0 \cdot 3(0 \cdot 3-0 \cdot 4)$ \\
\hline 1994 & $7 \cdot 1(6 \cdot 8-7 \cdot 3)$ & - & $0 \cdot 5(0 \cdot 5-0 \cdot 6)$ & $2 \cdot 4(2 \cdot 3-2 \cdot 5)$ & - & $0 \cdot 3(0 \cdot 3-0 \cdot 4)$ \\
\hline 1995 & $7 \cdot 5(7 \cdot 2-7 \cdot 7)$ & - & $0 \cdot 5(0 \cdot 5-0 \cdot 6)$ & $2 \cdot 5(2 \cdot 4-2 \cdot 6)$ & - & $0 \cdot 4(0 \cdot 3-0 \cdot 4)$ \\
\hline 1996 & $7 \cdot 9(7 \cdot 7-8 \cdot 2)$ & - & $0 \cdot 5(0 \cdot 5-0 \cdot 6)$ & $2 \cdot 7(2 \cdot 5-2 \cdot 8)$ & - & $0 \cdot 4(0 \cdot 3-0 \cdot 4)$ \\
\hline 1997 & $8 \cdot 4(8 \cdot 2-8 \cdot 7)$ & - & $0 \cdot 5(0 \cdot 5-0 \cdot 6)$ & $2 \cdot 8(2 \cdot 7-2 \cdot 9)$ & - & $0 \cdot 4(0 \cdot 3-0 \cdot 4)$ \\
\hline 1998 & $8 \cdot 9(8 \cdot 7-9 \cdot 2)$ & - & $0 \cdot 5(0 \cdot 5-0 \cdot 6)$ & $3 \cdot 0(2 \cdot 9-3 \cdot 1)$ & - & $0 \cdot 4(0 \cdot 3-0 \cdot 4)$ \\
\hline
\end{tabular}




\begin{tabular}{lllllll}
1999 & $9 \cdot 5(9 \cdot 3-9 \cdot 7)$ & - & $0 \cdot 5(0 \cdot 5-0 \cdot 6)$ & $3 \cdot 2(3 \cdot 1-3 \cdot 3)$ & - & $0 \cdot 4(0 \cdot 3-0 \cdot 4)$ \\
2000 & $10 \cdot 1(9 \cdot 8-10 \cdot 3)$ & - & $0 \cdot 5(0 \cdot 5-0 \cdot 6)$ & $3 \cdot 4(3 \cdot 2-3 \cdot 5)$ & - & $0 \cdot 4(0 \cdot 3-0 \cdot 4)$ \\
2001 & $10 \cdot 7(10 \cdot 4-10 \cdot 9)$ & - & $0 \cdot 5(0 \cdot 5-0 \cdot 6)$ & $3 \cdot 6(3 \cdot 4-3 \cdot 7)$ & - & $0 \cdot 4(0 \cdot 3-0 \cdot 4)$ \\
2002 & $11 \cdot 3(11 \cdot 1-11 \cdot 6)$ & $9 \cdot 1(8 \cdot 6-9 \cdot 7)$ & $0 \cdot 5(0 \cdot 5-0 \cdot 6)$ & $3 \cdot 8(3 \cdot 7-3 \cdot 9)$ & $3 \cdot 0(2 \cdot 7-3 \cdot 2)$ & $0 \cdot 4(0 \cdot 3-0 \cdot 4)$ \\
2003 & $12 \cdot 0(11 \cdot 8-12 \cdot 3)$ & $9 \cdot 8(9 \cdot 3-10 \cdot 3)$ & $0 \cdot 5(0 \cdot 5-0 \cdot 6)$ & $4 \cdot 0(3 \cdot 9-4 \cdot 2)$ & $3 \cdot 2(2 \cdot 9-3 \cdot 4)$ & $0 \cdot 4(0 \cdot 3-0 \cdot 4)$ \\
2004 & $12 \cdot 8(12 \cdot 5-13 \cdot 1)$ & $10 \cdot 5(10 \cdot 0-11 \cdot 0)$ & $0 \cdot 5(0 \cdot 5-0 \cdot 6)$ & $4 \cdot 3(4 \cdot 1-4 \cdot 4)$ & $3 \cdot 4(3 \cdot 2-3 \cdot 7)$ & $0 \cdot 4(0 \cdot 3-0 \cdot 4)$ \\
2005 & $13 \cdot 6(13 \cdot 3-13 \cdot 9)$ & $11 \cdot 3(10 \cdot 8-11 \cdot 8)$ & $0 \cdot 6(0 \cdot 5-0 \cdot 6)$ & $4 \cdot 5(4 \cdot 4-4 \cdot 7)$ & $3 \cdot 7(3 \cdot 4-3 \cdot 9)$ & $0 \cdot 4(0 \cdot 3-0 \cdot 4)$ \\
2006 & $14 \cdot 4(14 \cdot 1-14 \cdot 7)$ & $12 \cdot 1(11 \cdot 7-12 \cdot 6)$ & $0 \cdot 6(0 \cdot 5-0 \cdot 6)$ & $4 \cdot 8(4 \cdot 6-5 \cdot 0)$ & $3 \cdot 9(3 \cdot 7-4 \cdot 2)$ & $0 \cdot 4(0 \cdot 3-0 \cdot 4)$ \\
2007 & $15 \cdot 3(14 \cdot 9-15 \cdot 6)$ & $13 \cdot 0(12 \cdot 6-13 \cdot 5)$ & $0 \cdot 6(0 \cdot 5-0 \cdot 6)$ & $5 \cdot 1(4 \cdot 9-5 \cdot 3)$ & $4 \cdot 2(4 \cdot 0-4 \cdot 5)$ & $0 \cdot 4(0 \cdot 3-0 \cdot 4)$ \\
2008 & $16 \cdot 2(15 \cdot 8-16 \cdot 6)$ & $14 \cdot 0(13 \cdot 6-14 \cdot 4)$ & $0 \cdot 6(0 \cdot 5-0 \cdot 6)$ & $5 \cdot 4(5 \cdot 2-5 \cdot 6)$ & $4 \cdot 5(4 \cdot 3-4 \cdot 8)$ & $0 \cdot 4(0 \cdot 3-0 \cdot 4)$ \\
2009 & $17 \cdot 2(16 \cdot 7-17 \cdot 7)$ & $15 \cdot 0(14 \cdot 6-15 \cdot 5)$ & $0 \cdot 6(0 \cdot 5-0 \cdot 6)$ & $5 \cdot 7(5 \cdot 5-6 \cdot 0)$ & $4 \cdot 9(4 \cdot 6-5 \cdot 2)$ & $0 \cdot 4(0 \cdot 3-0 \cdot 4)$ \\
2010 & $18 \cdot 2(17 \cdot 7-18 \cdot 8)$ & $16 \cdot 2(15 \cdot 6-16 \cdot 7)$ & $0 \cdot 6(0 \cdot 5-0 \cdot 6)$ & $6 \cdot 1(5 \cdot 8-6 \cdot 4)$ & $5 \cdot 2(4 \cdot 9-5 \cdot 6)$ & $0 \cdot 4(0 \cdot 3-0 \cdot 4)$ \\
2011 & $19 \cdot 4(18 \cdot 8-19 \cdot 9)$ & $17 \cdot 4(16 \cdot 7-18 \cdot 0)$ & $0 \cdot 6(0 \cdot 5-0 \cdot 7)$ & $6 \cdot 5(6 \cdot 2-6 \cdot 8)$ & $5 \cdot 6(5 \cdot 3-6 \cdot 0)$ & $0 \cdot 4(0 \cdot 3-0 \cdot 4)$ \\
2012 & $20 \cdot 5(19 \cdot 9-21 \cdot 2)$ & $18 \cdot 6(17 \cdot 8-19 \cdot 5)$ & $0 \cdot 6(0 \cdot 5-0 \cdot 7)$ & $6 \cdot 9(6 \cdot 6-7 \cdot 2)$ & $6 \cdot 0(5 \cdot 6-6 \cdot 5)$ & $0 \cdot 4(0 \cdot 3-0 \cdot 5)$ \\
\hline
\end{tabular}


1 Original Research

2

3

Differentiated thyroid cancer: Millions spent with no tangible gain?

4

5 Running title: Increase in DTC incidence and thyroidectomy

6

7 Luis Furuya-Kanamori $P h D^{1}$, Professor Art Sedrakyan $P h D^{2,3}$, Adedayo A. Onitilo $P h D^{4}$,

Nasser Bagheri $P h D^{2}$, Professor Paul Glasziou $P h D^{5}$, Professor Suhail A.R Doi $P h D^{61^{*}}$

9

10

$11 \mid{ }^{1}$ Department of Populationublic MedicineHealth, College of MedicineHealth Seiences, Qatar 12 University, Doha, Qatar

$13{ }^{2}$ Research School of Population Health, Australian National University, Canberra, ACT, 14 Australia

$15{ }^{3}$ Department of Healthcare Policy \& Research, Weill Cornell Medicine, New York, NY, 16 USA

$17{ }^{4}$ Department of Hematology/Oncology, Marshfield Clinic Weston Center, Weston, WI, USA

$18{ }^{5}$ Centre for Research in Evidence Based Practice, Bond University, Gold Coast, QLD, 19 Australia

${ }^{6}$ Department of Population Medicine, College of Medicine, Qatar University, Doha, Qatar

$23 *$ Post-publication correspondence to:

24 Professor Suhail A.R. Doi MBBS, MMed, MClinEpid, PhD, FRCP

25 Department of Population Medicine, College of Medicine, Qatar University

26 2713, Al Hala St, Doha, Qatar

27 sardoi@gmx.net

28

29

30 Word count: 2574 


\section{Abstract}

32 Background: The incidence of differentiated thyroid cancer (DTC) has rapidly increased worldwide over the last decades. It is unknown if the increase in diagnosis has been mirrored by an increase in thyroidectomy rates with the concomitant economic impact that this would

35 have on the healthcare system.

Methods: DTC and thyroidectomy incidence as well as DTC specific mortality were modelled using Poisson regression in New South Wales (NSW), Australia per year and by sex. The incidence of 2002 was the point from which the increase in rates were assessed cumulatively over the subsequent decade. The economic burden of potentially avoidable thyroidectomies due to the increase in diagnosis was estimated as the product of the additional thyroidectomy procedures during a decade attributable to rates beyond those reported for 2002 and the national average hospital cost of an uncomplicated thyroidectomy in Australia.

Results: The incidence of both DTC and thyroidectomy doubled in NSW between 2003 and 2012, while the DTC specific mortality rate remained unchanged over the same period. Based on the 2002 incidence, the projected increase over 10 years (2003-2012) in thyroidectomy procedures was 2,196. This translates to an extra cost burden of over AUD\$ 18,600,000 in surgery-related healthcare expenditure over one decade in NSW.

Conclusions: Our findings suggest that, if this rise is solely attributable to overdetection, then the rising expenditure serves no additional purpose. Reducing unnecessary detection and a conservative approach to managing DTC are sensible and would lead to millions of dollars in savings and reduced harms to patients. 
57

58

59

\section{Introduction}

The incidence of thyroid cancer has increased worldwide 3- to 15-fold over the last two decades, but with no significant increase in mortality (Pellegriti et al., 2013, Ahn et al., 2014). The increase in incidence is largely attributable to increased detection of differentiated thyroid cancer ([DTC] - i.e. papillary and follicular cancer) (Burgess and Tucker, 2006, Davies and Welch, 2006, Enewold et al., 2011). Studies have found that the penetrance of thyroid-cancer screening and fine-needle aspiration (FNA) strongly correlate with the observed increase in incidence (Burgess and Tucker, 2006, Ahn et al., 2014). Our recent investigation has also found that the increasing incidence of DTC is not mirrored by the prevalence of incidental DTC in autopsy studies which has remained stable since 1970 (Furuya-Kanamori et al., 2016). These findings, especially given the latter, establish the case for the absence of a true population level increase in tumorigenesis and supports the notion that the increasing burden is driven by increasing detection (Davies and Welch, 2006, Welch and Black, 2010, Brito et al., 2014, Furuya-Kanamori et al., 2016).

Alongside this increase in DTC incidence, there are reports that suggest that subsequent surgical intervention (i.e. thyroidectomy) is also increasing (Sung et al., 2014, Ahn and Welch, 2015). For example, DTC overdetection, in small papillary carcinomas, is leading to unnecessary thyroidectomies with no real survival advantage delivered to patients (Davies and Welch, 2006, Enewold et al., 2011). After surgery most patients would require lifelong thyroid-replacement therapy, while some patients may have complications from the surgical procedure such as hypoparathyroidism and paralysis of recurrent or superior laryngeal nerves (Hartl and Schlumberger, 2013). Therefore, in March 2014 a Physician Coalition for Prevention of Overdiagnosis of Thyroid Cancer in South Korea wrote an open letter to the public discouraging routine ultrasonographicy screening, this recommendation 
81 led to a $40 \%$ decrease in thyroidectomies within the country in the subsequent year (Ahn and

82 Welch, 2015).

83 Similar to other countries, DTC incidence has rapidly increased over the last two 84 decades in Australia (Burgess, 2002, Haggar et al., 2012, Pandeya et al., 2016, Cancer

85 Australia); however, it is unknown if this has been paralleled by an increase in surgical 86 intervention rates. We therefore undertook an evaluation of the diagnostic, surgical, and 87 mortality trend data for DTC from New South Wales (NSW) to estimate the increase in 88 economic burden of these surgical interventions to the Australian healthcare system and its 89 impact on DTC specific mortality rates during the last decade. 
90

91

\section{Materials and methods}

The study was approved by the Australian National University - Science \& Medical Delegated Ethics Review Committee (\#2016/030) and conforms to the data-use agreement from the NSW Health Department.

\section{Data sources and study population}

Aggregated data from patients diagnosed with thyroid cancer (Cancer Institute NSW, 2016b) and thyroid cancer specific deaths (Cancer Institute NSW, 2016c) in NSW between January 1982 and December 2012 were retrieved from the Cancer Institute NSW. The NSW Cancer Registry (NSWCR) is managed by the Cancer Institute NSW. The NSWCR is a population-based cancer registry that contains records of people with malignant neoplasm $\underline{\text { in }}$ NSW since 1972. Notification of new cancer cases and cancer deaths is legally required in NSW and the NSWCR receives data from public and private hospitals, nursing homes, public and private pathology laboratories, and the Registry of Births, Deaths and Marriage.

Data from patients with thyroid gland malignancies (ICD-10-CM C73) that underwent partial (ICD-10-AM 30306-00, 30306-01, 30308-00, 30310-00, 90046-00) or total (ICD-10AM 30296-00, 30296-01, 90046-01, 90046-02) thyroidectomies between January 2002 and December 2012 in NSW were extracted from the Admitted Patient Data Collection (APDC). Thyroidectomies with indications other than thyroid cancer (i.e. thyrotoxicosis ICD-10-AM 30309-00) were excluded from the analysis. To avoid the inclusion of recurrent cases of surgical procedures (e.g. partial thyroidectomy followed by a total thyroidectomy - ICD-10AM 30297-00, 30297-01, 30297-02) and over estimating the incidence of patients that underwent a thyroidectomy; if a patient had more than one surgical procedure, only the first procedure was included for the analysis. The APDC is administered by the NSW Health Department. The APDC data provides reasonably accurate information on procedures and 
115 comorbidities (Goldsbury et al., 2011, Goldsbury et al., 2012). A detailed description of the

116 APDC scope, collection methodology, maintenance, and data accuracy is described 117 elsewhere (Australian Bureau of Statistics, 2008).

118 
119

120

121

122

\section{Statistical analyses}

Thyroid cancer cases, thyroidectomy procedures, and thyroid cancer specific mortality in NSW were categorized by year of event (diagnosis or surgical procedure) and sex. New events were counted within these categories. The population at risk, the population in $\mathrm{NSW}_{2}$ was extracted from the Australian Bureau of Statistics (ABS) and stratified by year and sex. It should be noted that differentiation of DTC from all thyroid cancers was not possible and this applies to thyroidectomy as well. Although, the analyses were not DTCspecific, yet the estimated incidence rates reported are deemed to be those for DTC as they should closely match the DTC-specific incidence due to the small proportion ( $10 \%$ or less) of other histological types of cancers (i.e. medullary and anaplastic) expected in such cohorts during the same period (Pandeya et al., 2016). This seems justified since In addition, we $\underline{\text { an }}$ analysised of a previous dataset of ours with only DTC and-confirmsed that DTC mortality trends indeed remained remain comparable identical with to thoseat reported here (Mankarios et al., 2014). All subsequent references to DTC should be understood to refer to DTC without exclusion of the other thyroid cancers.

Poisson regressions models using robust standard errors and the population as the exposed population at risk were built to model the rates for incident DTC, incident thyroidectomies, and thyroid cancer specific mortality in NSW by including an interaction term for continuous year and sex. The predicted number of cases per year and by sex from the fitted models were used to estimate the incidence of DTC and DTC specific mortality from 1982 to 2012 and thyroidectomy procedures from 2002 to 2012 in NSW per 100,000 population.

The rate observed in 2002 was deemed the baseline from which the increase in the rate of thyroidectomy was computed over the subsequent decade. The increase in thyroidectomy rates was therefore estimated for the period 2003-2012 as the difference from 
144 the baseline had it remained at the 2002 levels. To compute the additional number of surgical

145 procedures over the last decade, the modelled difference in rates (from 2002 levels) was

146 multiplied by the population at risk in NSW during each year.

147 The national average hospital cost of uncomplicated thyroidectomy for 2012-2013 in

148 Australia was AUD\$ 8,500 (Independent Hospital Pricing Authority, 2015). The economic

149 burden of potentially avoidable thyroidectomy due to the increase in diagnosis to the 150 Australian healthcare system was estimated as the product of the additional thyroidectomy 151 within the decade after 2002 and the national average hospital cost of an uncomplicated 152 thyroidectomy. We did not estimate the costs of complications or ongoing treatment such as 153 thyroid replacement. All statistical analyses were conducted using Stata ${ }^{\circledR}$ SE, version 14 154 (Stata Corporation; College Station, TX). 


\section{Results}

Between 1982 and 2012, 13,131 patients were diagnosed with DTC in NSW and 859 157 had a thyroid cancer specific mortality. The majority of diagnosed patients were females $(\mathrm{n}=9,877 ; 75 \cdot 1 \%) .6,790$ thyroidectomies were recorded among patients with DTC between 2002 and 2012 in NSW hospitals. The majority of the thyroidectomy procedures were performed in women $(\mathrm{n}=5,485 ; 80.89 \%)$ and the median age of the patients was 50 years (IQR 40-62 years) (Table 1).

The estimated DTC incidence per 100,000 population increased from 3.4 (females) and 1.2 (males) in 1982 to 20.6 (females) and 6.8 (males) in 2012. The estimated thyroidectomy incidence per 100,000 population increased from 9.1 (females) and 3.0 (males) in 2002 to 18.6 (females) and 6.0 (males) in 2012; while the estimated thyroid cancer happened if thyroidectomies rates had remained stable subsequent to 2002 . This translates to an increase of AUD\$ $18,666,000$ (\$14,169,500 in females; $\$ 4,496,500$ in males) in surgeryspecific mortality rate demonstrated no change over this period or indeed the prior two decades (Figures 1 and $2 \&$ Supplementary material).

During the decade of interest (2003-2012), there was a two-fold increase in both, DTC and thyroidectomies among females and males. Since, the percentage of DTC diagnosed patients getting a thyroidectomy has remained stable, therefore-it follows therefore that watchful waiting is not happening at a greater rate than previously despite DTC incidence steeply rising (Figures $1 \& 2$ ). Based on this increasing incidence, the projected increase in thyroidectomy was 2,196 (1,667 females; 529 males) cases more than would have related healthcare expenditure over one decade in NSW (Figures 1 and 2). 
177

178

179

180

181

182

183

\section{Discussion}

DTC incidence has increased to epidemic proportions worldwide over the last few decades. Overdetection has not only increased DTC incidence, but it has also led to a concurrent increase in thyroidectomy procedures with a huge economic burden on the healthcare system (Table 2). Over the last decade, we estimate that the number of potentially avoidable thyroidectomies performed in NSW was 2,196. The increase in thyroidectomy procedures in NSW over this decade actually approximates the total estimated number of new cases of thyroid cancer diagnosed Australia-wide in 2016 (2098 new cases) (Cancer Australia). DTC specific mortality in Australia however has remained essentially unchanged over the last 30 years (Cancer Australia) and among the thyroid cancer specific deaths recorded in 2012 in NSW, half of them occurred in patients aged 80 years or above (Cancer Institute NSW, 2016a). These figures amount to a huge excess in diagnosis and intervention that do not lead to increased survival for patients (Davies and Welch, 2006, Ito et al., 2010, Sugitani et al., 2010, Welch and Black, 2010, Ito et al., 2014, Furuya-Kanamori et al., 2016, Cancer Australia).

It should be emphasised that we base our conclusion regarding the lack of tangible clinical gain only on the specific mortality rate having remained unchanged ${ }_{5}$, There is, however, no expectation that intervention may decrease morbidity that does not lead to death. Unfortunately, these interventions themselves have been associated with morbidities. In fact, paradoxically there is likely to be an increase in morbidity related to treatment if patients subject to such (over)diagnosis are given the standard management for thyroid cancer which includes surgical resection and/or radioiodine therapy (Doi and Woodhouse, 2000, Doi et al., 2007, Haugen et al., 2015). Surgical complications may arise and include hypoparathyroidism, a life-threatening condition that requires intensive monitoring and therapy with calcium and vitamin D; laryngeal nerve palsy which will results in voice 
202 change; and/or require tracheotomy in cases of bilateral nerve damage. Even when the 203 surgery is complication free, most of the patients will require lifelong surveillance, and 204 thyroid hormone suppression or replacement which may have longer term metabolic implications (Hartl and Schlumberger, 2013).

It could be argued that the increased thyroid cancer diagnosis in recent years is associated with stable mortality because of improvement in diagnosis and management over time. However, Davies and Welch have pointed out that this is not likely to be true (Davies and Welch, 2014) because for mortality to remain stable, improvements (in diagnostic techniques and disease management) have to precisely mirror the increase in thyroid incidence. Thus, improvements occurring at a faster or slower rate than changes in incidence rate would certainly alter mortality rates and to assume an exact match between the rising incidence and the improvements over 30 years is highly implausible. In a previous study, we demonstrated that the reservoir of incidental DTC has remained stable since 1970 suggesting that population level of tumorigenesis has remained unchanged (Furuya-Kanamori et al., 2016). Therefore, the most reasonable explanation for the rising thyroid cancer incidence with stable mortality is that subclinical DTC is increasingly being detected due to the improvements in diagnostic techniques, but these newly diagnosed subclinical cases may not progress or will progress so slowly that the patient is more likely to die from other causes.

Overdetection of indolent DTC microcarcinomas could lead to unnecessary economic burden, while late diagnosis of clinically significant thyroid cancer could worsen clinical outcome. The current evidence does make the case for the development of strategies to reduce overdetection (the thyroid should not be examined without a specific indication) as well as implementation of a more conservative approach to nodule diagnosis through active surveillance leading on to intervention if thyroid nodules demonstrate progression (i.e. size and/or characteristics) (Leboulleux et al., 2016). At this point, it is not clear which patients 
227 are eligible for active surveillance, further studies are required to accurately discriminate 228 patients who need to undergo thyroid nodule biopsy or active surveillance; as well as to 229 recognise prognostic factors that would warrant early intervention among the subset of 230 thyroid cancer patients with more aggressive disease. Currently, nodule size is an important 231 factor in such decision making, along with family history, exposure to radiation, and age of 232 the patient (>45 years) (Onitilo et al., 2009, Mankarios et al., 2014, Haugen et al., 2015, 233 Hoang et al., 2015). Although, differentiation of DTC histopathology (papillary versus 234 follicular) does not seem to play a major role in decision making, FNA cytology may be 235 indicated if there are signs of progression or to differentiate DTC from other types of 236 carcinomas (i.e. medullary and anaplastic) given the different prognosis associated with the 237 latter.

In terms of health services expenditure, thyroid gland surgeries in Australia cost on average AUD\$ 8,500; however when there are surgical complications, this amount rapidly increases to over AUD\$15,000 (Independent Hospital Pricing Authority, 2015). We used the average cost of uncomplicated thyroidectomies, which provides a conservative economic estimate of the burden of increasing diagnosis. Future economic evaluations would need to take into account additional costs such as diagnosis (e.g. FNA and histopathology examination), complications during the surgical intervention (e.g. ICU admission), hormone replacement therapy, and outpatient consultations. Thus, a deferral of surgery can be expected to lead to significant savings in projected healthcare expenditure of at least AUD\$ 4 million per year in the state of NSW. This cost saving over 10 years is weighted heavily towards the later part of the decade and is a very conservative estimate as it does not take into account the treatment factors mentioned previously and of course the emotional burden on patients. Furthermore, given that the DTC incidence rise has been ongoing since the 1980s,

251 our estimate over only the last decade is probably a considerable underestimate of the 
252 economic burden as overdetection/thyroidectomy may have increased 4-fold rather than just 253 2-fold. While, the data suggest a clear economic case for surveillance rather than 254 intervention, and accumulated evidence from several studies suggest that this would be a safe 255 approach (Ito et al., 2010, Sugitani et al., 2010, Brito et al., 2014, Ito et al., 2014); the exact 256 process that should be adopted requires further evidence from prospective clinical studies, 257 and funding for such studies must be made a priority.

258 Our findings should be considered in the light of a few limitations. An important one 259 was the inability to conduct sub-group analyses by age group, patient ethnicity, tumour size, 260 and histopathology. However, we were able to stratify the analyses by sex, which is known to 261 be one of the strongest predictors of DTC incidence and thyroidectomy. We also make the smaller thyroid cancer. Another study from Spain by Rego-Iraeta et al. (2009) also reported that the rate of rise in thyroid cancer was observed across all tumour sizes. We agree with the latter that the incidence of all sizes are rising but a re-analysis of our previous data (Mankarios et al., 2014) stratified by tumour size and gender clearly demonstrates that the rate of rise decreases with increasing size, though all sizes are increasingly detected (data not shown). We believe that this again is consistent with overdiagnosis. Nevertheless, it is important to distinguish indolent tumours from clinically significant tumours (where delays in diagnosis are important) and this requires guidance from future studies regarding delineation of criteria for patients who need to undergo thyroid nodule biopsy for diagnosis of thyroid cancer (to avoid over-diagnosis of indolent thyroid cancer). Such criteria would likely

276 be prognostic factors that would assist in identification of more advanced thyroid cancers 
277 thus avoiding fears that clinicians may delay treatment and increase recurrent/persistent

278 disease within a selected sub-set of thyroid cancer patients with more aggressive disease.

279 In conclusion, the evidence base for avoidable costs to healthcare is clear and savings 280 expected are substantial from a conservative approach to both thyroid examination (only 281 when indicated) and management of thyroid cancer when detected. Current evidence suggests 282 that watchful waiting is a safe route for management of many of the latter patients if due 283 surveillance is properly managed. What remains to be mapped out is who exactly should be 284 offered active surveillance and the criteria for subsequent intervention. 


\section{Declaration of interest}

286 The authors have no conflicts of interest in the authorship or publication of this article.

\section{Funding}

289 None

290

291 Authors' contributions

292 LFK and SARD contributed to the conception and design of the study. AS and LFK assisted 293 with data acquisition. LFK conducted the statistical analyses. LFK and SARD drafted the 294 manuscript. AS, AAO, NB, and PG critically revised the manuscript. LFK, AS, AAO, NB, 295 PG, and SARD read and approved the final version of the manuscript and agreed to be fully 296 accountable for ensuring the integrity and accuracy of the work. 
297

298

299

300

301

302

303

304

305

306

307

308

309

310

311

312

313

314

315

316

317

318

319

320

321

322

323

324

325

\section{References}

AHN, H. S., KIM, H. J. \& WELCH, H. G. 2014. Korea's thyroid-cancer "epidemic"screening and overdiagnosis. $N$ Engl J Med 371: 1765-7.

AHN, H. S. \& WELCH, H. G. 2015. South Korea's thyroid-cancer "Epidemic"- Turning the tide. $N$ Engl J Med 373: 2389-90.

AUSTRALIAN BUREAU OF STATISTICS. 2008. NSW Health Department, Admitted Patient Data Collection [Online]. Available: http://www.abs.gov.au/AUSSTATS/abs@.nsf/Lookup/1368.1Explanatory\%20Notes1 $\underline{452007}$ [Accessed September 2017].

BRITO, J. P., DAVIES, L., ZEBALlOS-PALACIOS, C., MORRIS, J. C. \& MONTORI, V. M. 2014. Papillary lesions of indolent course: reducing the overdiagnosis of indolent papillary thyroid cancer and unnecessary treatment. Future Oncol 10: 1-4.

BURGESS, J. R. 2002. Temporal trends for thyroid carcinoma in Australia: an increasing incidence of papillary thyroid carcinoma (1982-1997). Thyroid 12: 141-9.

BURGESS, J. R. \& TUCKER, P. 2006. Incidence trends for papillary thyroid carcinoma and their correlation with thyroid surgery and thyroid fine-needle aspirate cytology. Thyroid 16: 47-53.

CANCER AUSTRALIA. Thyroid cancer [Online]. Available: https://canceraustralia.gov.au/affected-cancer/cancer-types/thyroid-cancer/thyroidcancer-statistics [Accessed September 2017].

CANCER INSTITUTE NSW. 2016a. Thyroid cancer [Online]. Available: https://www.cancerinstitute.org.au/understanding-cancer/cancer-in-nsw/thyroidcancer [Accessed September 2017].

CANCER INSTITUTE NSW. 2016b. Thyroid cancer - Age Standardised Incidence Rates [Online]. Available: http://www.statistics.cancerinstitute.org.au/trends/trends_incid_C73_extall_NSW.htm [Accessed September 2017].

CANCER INSTITUTE NSW. 2016c. Thyroid cancer - Age Standardised Mortality Rates [Online].

Available: 

http://www.statistics.cancerinstitute.org.au/trends/trends_mort_C73 extall_NSW.htm [Accessed September 2017].

DAVIES, L. \& WELCH, H. 2014. Davies and welch draw unfounded conclusions about thyroid cancer from epidemiological data-reply. JAMA Otolaryngol Head Neck Surg 140: 679 .

DAVIES, L. \& WELCH, H. G. 2006. Increasing incidence of thyroid cancer in the United States, 1973-2002. JAMA 295: 2164-7.

DOI, S. A. \& WOODHOUSE, N. J. 2000. Ablation of the thyroid remnant and 131I dose in differentiated thyroid cancer. Clin Endocrinol (Oxf) 52: 765-73.

DOI, S. A. R., WOODHOUSE, N. J., THALIB, L. \& ONITILO, A. 2007. Ablation of the Thyroid Remnant and I-131 Dose in Differentiated Thyroid Cancer: A Meta-Analysis Revisited. Clin Med Res 5: 87-90.

ENEWOLD, L., ZHU, K., RON, E., MARROGI, A. J., STOJADINOVIC, A., PEOPLES, G. E. \& DEVESA, S. S. 2009. Rising thyroid cancer incidence in the United States by demographic and tumor characteristics, 1980-2005. Cancer Epidemiol Biomarkers Prev 18: 784-91.

ENEWOLD, L. R., ZHOU, J., DEVESA, S. S., BERRINGTON DE GONZALEZ, A., ANDERSON, W. F., ZAHM, S. H., STOJADINOVIC, A., PEOPLES, G. E., MARROGI, A. J., POTTER, J. F., MCGLYNN, K. A. \& ZHU, K. 2011. Thyroid cancer incidence among active duty U.S. military personnel, 1990-2004. Cancer Epidemiol Biomarkers Prev 20: 2369-76.

FURUYA-KANAMORI, L., BELL, K. J., CLARK, J., GLASZIOU, P. \& DOI, S. A. 2016. Prevalence of Differentiated Thyroid Cancer in Autopsy Studies Over Six Decades: A Meta-Analysis. J Clin Oncol 34: 3672-9.

GOldSBURY, D. E., ARMSTRONG, K., SimOnElla, L., ARMSTRONG, B. K. \& O'CONNELL, D. L. 2012. Using administrative health data to describe colorectal and lung cancer care in New South Wales, Australia: a validation study. BMC Health Serv Res 12: 1472. 
GOLDSBURY, D. E., SMITH, D. P., ARMSTRONG, B. K. \& O'CONNELL, D. L. 2011. Using linked routinely collected health data to describe prostate cancer treatment in New South Wales, Australia: a validation study. BMC Health Services Res 11: 253.

HAGGAR, F. A., PREEN, D. B., PEREIRA, G., HOLMAN, C. D. \& EINARSDOTTIR, K. 2012. Cancer incidence and mortality trends in Australian adolescents and young adults, 1982-2007. BMC Cancer 12: 151.

HARTL, D. M. \& SCHLUMBERGER, M. 2013. Extent of Thyroidectomy and Incidence of Morbidity: Risk-appropriate Treatment. In: MICCOLI, P., TERRIS, D. J., MINUTO, M. N. \& SEYBT, M. W. (eds.) Thyroid Surgery: Preventing and Managing Complications. Oxford: Wiley-Blackwell.

HAUGEN, B. R. M., ALEXANDER, E. K., BIBLE, K. C., DOHERTY, G., MANDEL, S. J., NIKIFOROV, Y. E., PACINI, F., RANDOLPH, G., SAWKA, A., SCHLUMBERGER, M., SCHUFF, K. G., SHERMAN, S. I., SOSA, J. A., STEWARD, D., TUTTLE, R. M. M. \& WARTOFSKY, L. 2015. 2015 American Thyroid Association management guidelines for adult patients with thyroid nodules and differentiated thyroid cancer. Thyroid 26: 1-133.

HOANG, J. K., LANGER, J. E., MIDDlETON, W. D., WU, C. C., HAMMERS, L. W., CRONAN, J. J., TESSLER, F. N., GRANT, E. G. \& BERLAND, L. L. 2015. Managing incidental thyroid nodules detected on imaging: white paper of the ACR Incidental Thyroid Findings Committee. J Am Coll Radiol 12: 143-50.

INDEPENDENT HOSPITAL PRICING AUTHORITY. 2015. National Hospital Cost Data Collection Australian Public Hospitals Cost Report 2012-2013, Round 17 [Online]. Available:

https://www.ihpa.gov.au/sites/g/files/net636/f/publications/nhcde cost report_20122013 round_17_0.pdf [Accessed September 2017].

ITO, Y., MIYAUCHI, A., INOUE, H., FUKUSHIMA, M., KIHARA, M., HIGASHIYAMA, T., TOMODA, C., TAKAMURA, Y., KOBAYASHI, K. \& MIYA, A. 2010. An observational trial for papillary thyroid microcarcinoma in Japanese patients. World $J$ Surg 34: 28-35. 
ITO, Y., MIYAUCHI, A., KIHARA, M., HIGASHIYAMA, T., KOBAYASHI, K. \& MIYA, A. 2014. Patient age is significantly related to the progression of papillary microcarcinoma of the thyroid under observation. Thyroid 24: 27-34.

LEBOUllEUX, S., TUTTLE, R. M., PACINI, F. \& SCHLUMBERGER, M. 2016. Papillary thyroid microcarcinoma: time to shift from surgery to active surveillance? Lancet Diabetes Endocrinol 4: 933-42.

MANKARIOS, D., BAADE, P., YOUL, P., MORTIMER, R. H., ONITILO, A. A., RUSSELL, A. \& DOI, S. A. 2014. Validation of the QTNM staging system for cancer-specific survival in patients with differentiated thyroid cancer. Endocrine 46: 300-8.

ONitilo, A. A., ENGEL, J. M., LUNDGREN, C. I., HALl, P., THALIB, L. \& DOI, S. A. 2009. Simplifying the TNM system for clinical use in differentiated thyroid cancer. $J$ Clin Oncol 27: 1872-8.

PANDEYA, N., MCLEOD, D. S., BALASUBRAMANIAM, K., BAADE, P. D., YOUL, P. H., BAIN, C. J., ALLISON, R. \& JORDAN, S. J. 2016. Increasing thyroid cancer incidence in Queensland, Australia 1982-2008 - true increase or overdiagnosis? Clin Endocrinol 84: 257-64.

PELlEGRITI, G., FRASCA, F., REGALBUTO, C., SQUATRITO, S. \& VIGNERI, R. 2013. Worldwide increasing incidence of thyroid cancer: Update on epidemiology and risk factors. J Cancer Epidemiol 2013: 965212.

REGO-IRAETA, A., PEREZ-MENDEZ, L. F., MANTINAN, B. \& GARCIA-MAYOR, R. V. 2009. Time trends for thyroid cancer in northwestern Spain: true rise in the incidence of micro and larger forms of papillary thyroid carcinoma. Thyroid 19: 33340.

SUGITANI, I., TODA, K., YAMADA, K., YAMAMOTO, N., IKENAGA, M. \& FUJIMOTO, Y. 2010. Three distinctly different kinds of papillary thyroid microcarcinoma should be recognized: our treatment strategies and outcomes. World J Surg 34: 1222-31. 
411 SUNG, M. W., PARK, B., AN, S. Y., HAH, J. H., JUNG, Y. H. \& CHOI, H. G. 2014.

412 Increasing thyroid cancer rate and the extent of thyroid surgery in Korea. PLoS One 9:

413 e113464.

414 WELCH, H. G. \& BLACK, W. C. 2010. Overdiagnosis in cancer. J Natl Cancer Inst 102: $415 \quad 605-13$.

416 
417 Table Title

418

419 Table 1. Patient's characteristics

420

421

Table 2. Worldwide trends in thyroid cancer incidence, thyroidectomy rate and mortality rate

422

423

424

425 Figure Legend

426

427 Figure 1. Observed (circles) and modelled (dashed lines) incidence per 100,000 for DTC 428 (blue), thyroidectomies (red), and DTC specific mortality (green) over time in females. Gray 429 shaded area represents the excess (potentially avoidable) thyroidectomies performed due to 430 the increase in diagnosis over the last decade and the excess in surgery-related healthcare 431 expenditure associated with this.

432

433 Figure 2. Observed (circles) and modelled (dashed lines) incidence per 100,000 for DTC 434 (blue), thyroidectomies (red), and DTC specific mortality (green) over time in males. Gray 435 shaded area represents the excess (potentially avoidable) thyroidectomies performed due to 436 the increase in diagnosis over the last decade and the excess in surgery-related healthcare 437 expenditure associated with this. 